\section{RESPIRABLE QUARTZ (AND FELDPARS) IN EQUINE RIDING ARENAS: SETTING THE STAGE FOR A ONE-HEALTH RISK ANALYSIS}

\author{
PROF. ELENA BELLUSO SR. ${ }^{1}$, TOMMASO BARONI ${ }^{2}$, \\ DONATA BELLIS ${ }^{3}$, MICHELA BULLONE ${ }^{4}$, SILVANA \\ CAPELLA $^{5}$ AND FRANCESCO DI BENEDETTO ${ }^{6}$ \\ $1_{\text {via Valperga Caluso } 35}$ \\ ${ }^{2}$ University of Florence \\ ${ }^{3}$ Department of Surgery, Pathological Anatomy, Ospedale degli \\ Infermi, Ponderano, Biella, Italy \\ ${ }^{4}$ Department of Veterinary Sciences, University of Torino, \\ Torino, Italy \\ ${ }^{5}$ University of Torino \\ ${ }^{6}$ University of Ferrara \\ Presenting Author: elena.belluso@unito.it
}

Footing surfaces used in equine riding arenas are composed by sand, either in the presence or absence of specific additives (e.g., organic or synthetic fibers, wood, rubber, etc.). Sand is made up of minerals such as, most commonly, quartz (sometimes cristobalite), feldspars, and carbonates.

The current guidelines on footing surfaces to be employed in the equine industry are mainly focused on their impact on the musculoskeletal structures of the horse and on their contribution to both horse and rider safety. As a matter of fact, they completely disregard their possible role as a source of respirable mineral particles and the effects such dispersion in air could have on both human and animal health.

Among the published literature, a single paper currently deals with the possible occupational exposure to respirable dust and respirable crystalline silica (RCS) in an Irish equestrian centre [1]. Besides, one case report relates lung cancer with exposure to RCS in a horse trainer [2]. Less data are available in horses, but evidence exists that horses react as well to RCS exposure by developing pulmonary silicosis [3].

Following a diagnostic suspect of silicosis in 3 ponies used for children equestrian activities in a riding arena near Turin (NW Italy) and showing compatible history as well as clinical and radiographic signs, samples were obtained of their tracheal and bronchoalveolar secretions (lavages) and of the footing surfaces used in their current and past barns (sand).

The sand was investigated both by SEM-EDS and XRPD to respectively define size and morphology of grains and to identify the nature and amount of different mineral species, respectively. Quartz, feldspars and several phyllosilicate were found in both respiratory samples (size range: 1-8 $\mu \mathrm{m}$ ) and in the footing surfaces assessed (size range: $15 \mu \mathrm{m}-0,3 \mathrm{~mm}$ ).

This case-report highlights the need of a detailed investigation on the possible health risk for personnel employed in the equine industry and pleasure riders, particularly children.

[1] Bulfin et al. (2019), Int J Environ Res Public Health 16(17), 3226 